\title{
Experimentation and Prediction of Temperature Rise in Turning Process using Response Surface Methodology
}

\author{
Zeelan Basha $\mathbf{N}^{\star}$, Semegn Cheneke and Geleta Fekadu
}

\author{
Department of Mechanical Engineering, College of Engineering and Technology, Post Box No: 395, \\ Wollega University, Nekemte, Ethiopia
}

\begin{tabular}{lll}
\hline & Abstract & Article Information \\
\hline Reducing the temperature rise during turning operation improves the quality of the product and & Article History: \\
reduces tool wear. Experiments are conducted as per the Design of Experiments (DoE) of & Received : $17-10-2014$ \\
Response Surface Methodology (RSM) to predict the temperature rise by varying the cutting & Revised $: 23-12-2014$ \\
parameters such as cutting speed, feed rate and depth of cut. In the present study, the & Accepted :30-12-2014 \\
\cline { 2 - 2 } experiment was conducted on Aluminium Al 6061 by coated carbide tool. A second order & Keywords: \\
mathematical model in terms of machining parameters was developed for temperature rise & Aluminium 6061 \\
prediction using RSM. This model gives the factor effects of the individual process parameters. & Cutting speed \\
Values of Prob> F less than 0.05 indicate model terms are significant. The cutting speed is the & Prediction \\
most important parameter that cause the temperature of the turning process compared to the & RSM \\
other factors such as feed rate and depth of cut. Validation results show good agreement & Zeelan Basha N Author: \\
between the actual process output and the predicted temperature rise. & E-mail: \\
Copyright@2014 STAR Journal. All Rights Reserved. & zeelu6@gmail.com \\
\hline
\end{tabular}

\section{INTRODUCTION}

Optimization of operating parameters is a vital step in machining, particularly for operating Computer Numerical Control (CNC) machine tools. Many researchers have investigated machining optimization problems. In this research effective optimization techniques approach response surface methodology is utilized for finding the optimal cutting conditions for best minimum temperature rise and also developed second order mathematical model for process parameters and analysis of variance measured for process parameters to ensure the significant effects.

Experiments are conducted as per the Design of Experiments (DoE) of Response Surface Methodology (RSM) to predict the spindle and work table vibration by varying the tool geometry parameter i.e., radial rake angle and cutting conditions (Spindle speed, feed rate, radial and axial depth of cut) in the end mill cutter. The experiment was conducted on Aluminium Al 6063 by HSS end mill cutter. This model gives the factor effects of the individual process parameters. Values of Prob> $F$ less than 0.05 indicate model terms are significant (Mahesh et al., 2012)

The response surface methodology (RSM) is a traditional technique for experimental process optimization. For the RSM, an experimental design was chosen and tests were performed in order to generate the proper models. Results indicate that both methods are capable of locating optimum conditions, with a relatively small number of experiments (Davi Sampaio Correia et al., 2005).The parameters that influence the quality of laser transmission joining were optimized using response methodology for achieving good joint strength and minimal joint width. The central composite second-order Rotational Design (CCRD) has been utilized to plan the experiments and response surface methodology (RSM) is employed to develop mathematical relationships between joining parameters and desired responses. The experimental values nearly agree with the predicted values from mathematical models, indicate that the models can predict the responses adequately and optimize the key process parameters quickly (Xiao Wang et al., 2012)

Response surface methodology (RSM) with the help of Design Expert Version 7.1.6 (STAT-EASE Inc., USA) was used for optimization of the extraction process and evaluation of interaction effects of different operating parameters (Keka Sinha et al., 2012). This study intends to determine the optimal cutting parameters required to minimize the cutting time while maintaining an acceptable quality level. This equation can be determined by studying the output cutting times vs. input cutting parameters through CATIA software, with assistance from the statistical method, response surface Methodology (RSM) (Angus Jeang, 2011)

A predictive model for laser turning process parameters is created using a feed-forward artificial neural network (ANN) technique utilized the experimental observation data based on response surface methodology (RSM) (Dhupal et al., 2009). ANOVA was employed to identify the level of importance of the machining 
Zeelan Basha et al.,

parameters (Gaitonde et al., 2008).Response surface methodology (RSM) is used for modeling whereas multiobjective optimization is performed using hybrid approach of TM and grey relational analysis (GRA) coupled with entropy measurement methodology. The results indicate that the hybrid approaches applied for modeling and optimization of the LBC process are reasonable (Amit Sharmaet et al., 2012)

The used parameters such as helix angle of cutter, spindle speed, feed rate, axial and radial depth of cut on temperature rise in end milling (Sivasakthivel et al., 2013). The development and utilization of an optimization system, which determines optimum machining parameters for milling operations (Baskar et al., 2005). In this work a mathematical model has been developed based on both the material behavior and the machine dynamics to determine cutting force for milling operations (Palanisamy, et al., 2007).The experimentation work to determine the effects of cutting conditions and tool geometry on the surface roughness in the finish hard turning of the bearing steel (AISI 52100) (Dilbag Singh et al., 2007)

Most published studies on metal cutting regard the cutting speed as having the greatest influence on tool wear and, thus, tool life, while other parameters and characteristics of the cutting process have not attracted as much attention in this respect (Viktor P. Astakhov,2007)

The design variables used in this research such as depth of cut, cutting speed and the feed rate in each pass. Bounds on depth of cut, cutting speed, feed; surface finishing, cutting force, cutting power and tool life were considered as technological constraints (Conceicao Antonio et al., 2009). The second-order mathematical models, in terms of the machining parameters for each of these five roughness parameters prediction using response surface method on the basis of experimental results (Routara et al., 2009).

The literature indicated above reveals that not much work has been reported on prediction and optimization of temperature rise in turning operation. The main objective of this research is to develop a model based on response surface methodology to the cutting temperature rise in terms of machining parameters such as cutting speed, feed rate, and depth of cut. During turning process, the cutting temperature rise is measured using pyrometer. The second order mathematical model helped us to study the direct and interaction effect of each parameter to ensure the significant effects.

\section{Response Surface Methodology (RSM)}

Response surface method (RSM) is the combination of experimental and statistical techniques which are useful for the modeling and analysis of problems in which a response of interest is influenced by several variables. RSM saves cost and time by reducing the number of experiments required for investigation. In this RSM technique, the main objective is to optimize the response i.e temperature rise which is influenced by cutting parameters using design expert software. A second order regression equation is developed. The (Fig.1) flow chart has given to understand the methodology used to study the effect of important parameters:
Sci. Technol. Arts Res. J., Oct-Dec 2014, 3(4): 158-164

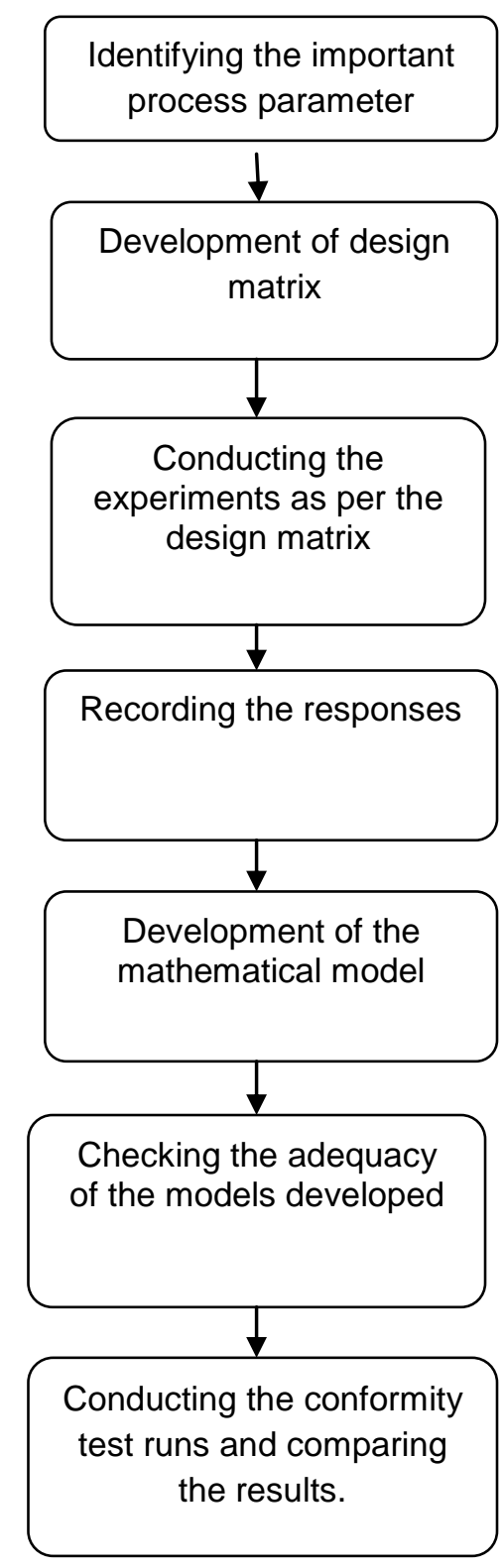

Figure 1: Methodology of optimization

\section{MATERIALS AND METHODS}

\section{Experimental Designs}

Response surface methodology is the most effective method to analyze the results obtained from factorial experiments. It is an effective tool for modeling and analyzing the engineering problems. It provides more information with less number of experimentation. In most of the RSM problems, the form of the relationship between the response and the independent variables is unknown (Routara et al., 2009)

The limit of the process parameters has to be defined in response surface methodology and the initial experimentation was done to identify the machining parameters that affect the temperature rise and to explore the range of the selected machining parameters (Sivasakthivel et al., 2013). In the present work, cutting speed, feed rate, depths of cut have been considered as the machining parameters. The response temperature rise $\mathrm{T}$ can be expressed as a function of process parameters cutting speed $\left(X_{1}\right)$, feed rate $\left(X_{2}\right)$, and depth of cut $\left(X_{3}\right)$. 


\section{Zeelan Basha et al.,}

Temperature Rise $=\phi\left(\mathrm{X}_{1}, \mathrm{X}_{2}, \mathrm{X}_{3}\right)+\mathrm{e}_{\mathrm{ui}}$

Where $\phi$ is the response surface, $e_{u i}$ is the residual, $u$ is the number of observations in the factorial experiment and ui represents level of $u^{\text {th }}$ observation in the $i^{\text {th }}$ factor. When the mathematical form of $\phi$ is unknown, this function can be approximated satisfactorily within the experimental region by polynomials in terms of the process parameter variable.

In statistics, Box-Behnken designs are experimental designs for response surface methodology, devised by George E.P. Box and Donald Behnken in 1960.Each factor, or independent variable, is placed at one of three equally spaced values, usually coded as $-1,0,+1$. In each block, a certain number of factors are put through all combinations for the factorial design, while the other factors are kept at the central values. It has three factors-three levels Box-Behnken rotatable design consisting of 17 sets of actual conditions (Table 1). The design of experiment with response as shown in (Table 2)

Table1: Process Parameters and their Levels

\begin{tabular}{|c|c|c|c|c|c|}
\hline No & Cutting parameters & unit & -1 & 0 & 1 \\
\hline 1 & Cutting speed $\left(\mathrm{X}_{1}\right)$ & $\mathrm{m} / \mathrm{min}$ & 90 & 110 & 120 \\
\hline 2 & Feed rate $\quad\left(\mathrm{X}_{2}\right)$ & $\mathrm{mm} / \mathrm{rev}$ & 0.18 & 0.27 & 0.36 \\
\hline 3 & Depth of cut $\left(X_{3}\right)^{-}$ & $\mathrm{mm}$ & 0.2 & 0.4 & 0.6 \\
\hline
\end{tabular}

\section{Experimental Procedure}

The (figure2) experiments were conducted based on the design of experiments using XLTURN-CNC lathe. The specification of the XLTURN-cnc lathe has been given below

Specification: Control system-fanuc emulated

Spindle power-1Hp

Spindle speed-100 to $3000 \mathrm{rpm}$

Max. Turning dia-32mm

Rapid traverse rate- $1.2 \mathrm{~m} / \mathrm{min}$

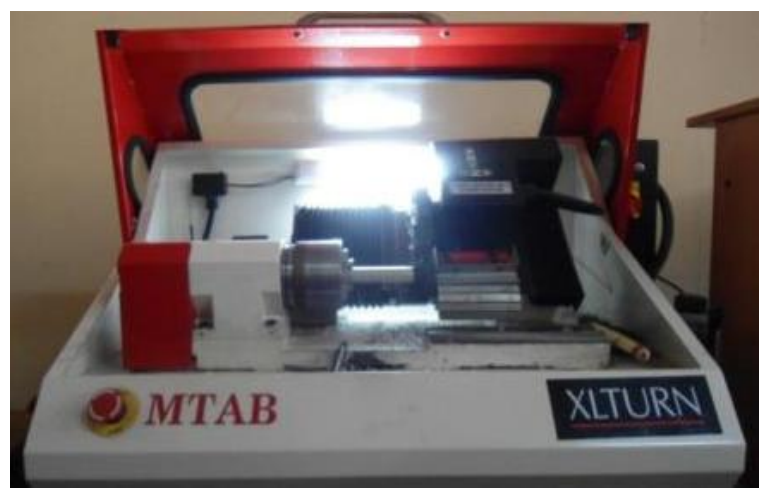

Figure 2: $X L T U R N-c n c$ lathe

The figure 3 suitable tool insert has been selected from the tool selection guide. The model tool AK10 Carbide Inserts turning Ground and Polished for Aluminium Uni-tip was used for turning process.

The figure 4 work material used for the turning process is aluminium 6061 and the material hardness has been tested, found to be $43 \mathrm{HRC}$. The chemical composition of aluminium 6061 (Table 3 )
Sci. Technol. Arts Res. J., Oct-Dec 2014, 3(4): 158-164

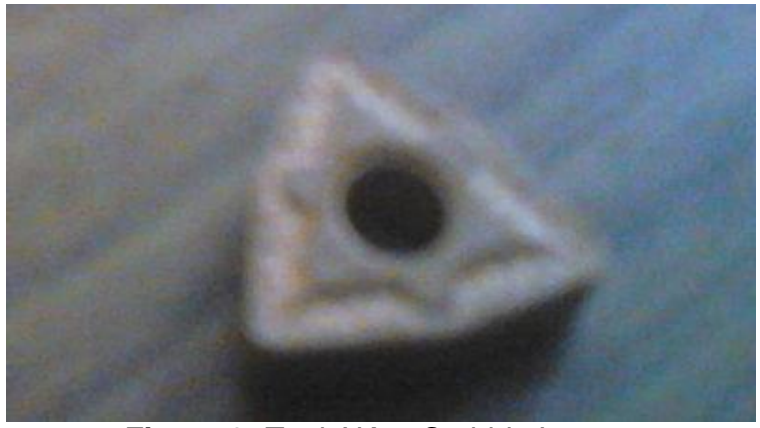

Figure 3: Tool AK10 Carbide Inserts

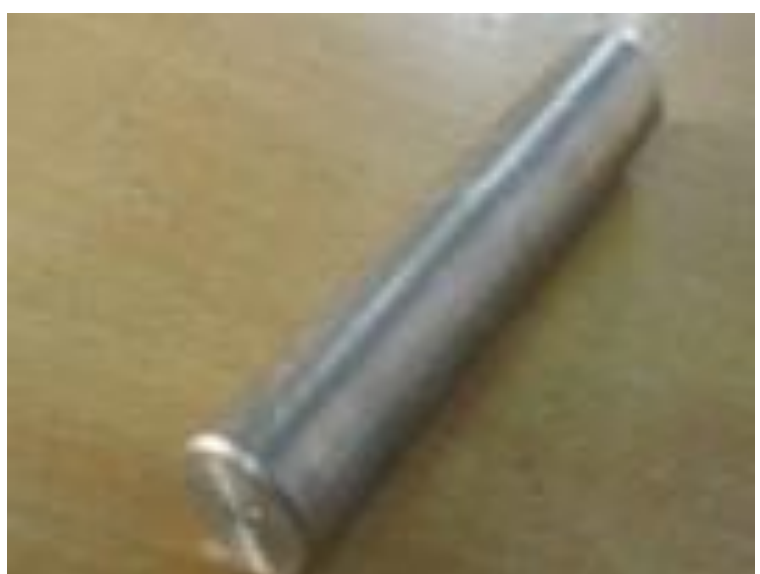

Figure 4: Workpiece material aluminium6061

The work piece material was Aluminium alloy (Al 6061) commonly available machinable metal which finds application in many manufacturing industries such as aircraft and aerospace components, marine fittings, transport, bicycle frames, drive, shafts, electrical fittings and connectors, brake components, valves, couplings. The dimension of the work piece specimen was $40 \mathrm{~mm}$ diameter and $100 \mathrm{~mm}$ in length. A pyrometer is a type of thermometer used to measure high temperatures. In the modern usage, it is a non-contacting device that intercepts and measures thermal radiation. By using digital pyrometer, the initial temperature was noted and during machining, the maximum temperature was measured, the difference between the maximum and initial temperature gave the temperature rise (figure 5).

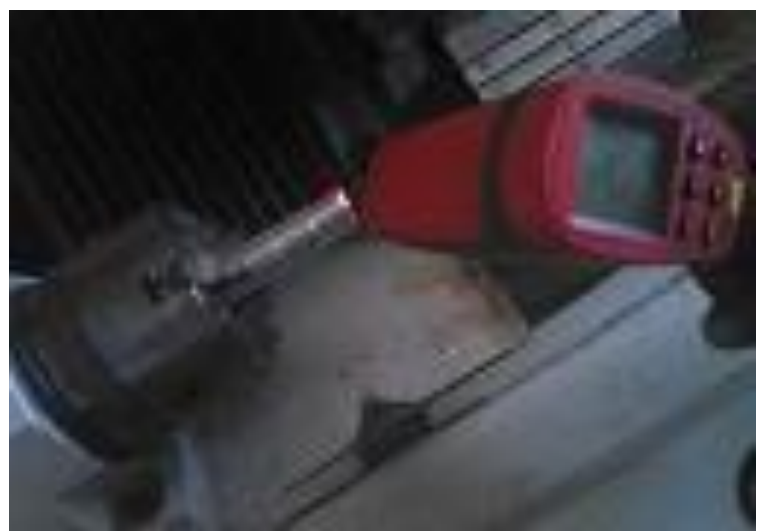

Figure 5: Digital pyrometer measures temperature

The temperature was measured by using pyrometer and the observations are tabulated to obtain the mathematical model (Table 2). 
Table 2: Experimental values with responses

\begin{tabular}{|c|c|c|c|c|}
\hline \multicolumn{3}{|c|}{ Cutting parameter } & \multicolumn{2}{|c|}{ Responses } \\
\hline $\begin{array}{c}\text { Cutting speed } \\
\mathrm{m} / \mathrm{min}\end{array}$ & $\begin{array}{c}\text { Feed rate } \\
\mathrm{mm} / \mathrm{rev}\end{array}$ & $\begin{array}{c}\text { Depth of cut } \\
\text { mm }\end{array}$ & $\begin{array}{c}\text { Temperature } \\
\text { Rise }{ }^{\circ} \mathrm{C} \text { (observed) }\end{array}$ & $\begin{array}{c}\text { Temperature } \\
\text { Rise }{ }^{\circ} \mathbf{C} \text { (predicted) }\end{array}$ \\
\hline 90.00 & 0.27 & 0.60 & 27.2 & 27.68 \\
\hline 105.00 & 0.27 & 0.40 & 22.3 & 23.76 \\
\hline 105.00 & 0.36 & 0.60 & 23.6 & 26.50 \\
\hline 90.00 & 0.36 & 0.40 & 32.3 & 28.93 \\
\hline 105.00 & 0.27 & 0.40 & 25.3 & 23.76 \\
\hline 105.00 & 0.18 & 0.60 & 22.5 & 21.15 \\
\hline 120.00 & 0.18 & 0.40 & 24.6 & 27.98 \\
\hline 105.00 & 0.18 & 0.20 & 23.6 & 20.90 \\
\hline 90.00 & 0.27 & 0.20 & 28.5 & 30.53 \\
\hline 90.00 & 0.18 & 0.40 & 26.3 & 27.18 \\
\hline 120.00 & 0.36 & 0.40 & 38.2 & 37.32 \\
\hline 120.00 & 0.27 & 0.60 & 37.4 & 35.38 \\
\hline 105.00 & 0.27 & 0.40 & 23.6 & 23.76 \\
\hline 105.00 & 0.27 & 0.40 & 23.4 & 23.76 \\
\hline 105.00 & 0.36 & 0.20 & 25.1 & 26.45 \\
\hline 105.00 & 0.27 & 0.40 & 24.2 & 23.76 \\
\hline 120.00 & 0.27 & 0.20 & 32.5 & 32.05 \\
\hline
\end{tabular}

Table 3: Chemical composition for Aluminium 6061

\begin{tabular}{cccccccccc}
\hline Al 6061 & Al & $\mathbf{S i}$ & $\mathbf{F e}$ & $\mathbf{C u}$ & $\mathbf{M n}$ & $\mathbf{M g}$ & $\mathbf{C r}$ & $\mathbf{Z n}$ & $\mathbf{T i}$ \\
\hline Weight (\%) & Balance & $0.40-0.80$ & $0.70 \max$ & $0.15-0.40$ & 0.15 & $0.8-1.2$ & $0.04-0.35$ & $0.25 \max$ & $0.15 \max$ \\
\hline
\end{tabular}

\section{Development of Mathematical Model}

In statistics, regression analysis is a statistical process for estimating the relationships among variables. It includes many techniques for modeling and analyzing several variables, when the focus is on the relationship between a dependent variable and one or more independent variables. The general form of a quadratic polynomial which gives the relation between response surface $\mathrm{y}$ and the process variable $\mathrm{x}$ under investigation is given by

$Y=\beta_{0}+\beta_{1} x_{1}+\beta_{2} x_{2}+\beta_{3} x_{3}+\beta_{11} x_{1}{ }^{2}+\beta_{22} x_{2}{ }^{2}+\beta_{12} x_{1} \ldots$ - - equ. 1

Where $\beta_{0}$ is a constant, $\beta_{1}, \beta_{2}, \beta_{3}$ is the linear term coefficient, $\beta_{11}, \beta_{22}$ is the quadratic term coefficient and $\beta_{12}$ is the interaction term coefficient (Sivasakthivel et al., 2013).

Regression equations (equ.2) were formed using values of the coefficients of the polynomials .A statistical software design expert 8.0was used to calculate the values of these coefficients. The second order mathematical model is developed using the experimental values and responses by neglecting the insignificant coefficients to predict the temperature rise $(T)$.

Temperature rise $(T)=407.17500-7.10200^{*} X_{1}-77.72222$ ${ }^{*} X_{2}-62.02500{ }^{*} X_{3}+1.40741{ }^{*} X_{1}{ }^{*} X_{2}+0.51667{ }^{*} X_{1}{ }^{*} X_{3}-5.55556 *$ $\mathrm{X}_{2}^{*} \mathrm{X}_{3}+0.031756^{*} \mathrm{X}_{1}^{2}-68.51852^{*} \mathrm{X}_{2}^{2}+12.37500^{*} \mathrm{X}_{3}^{2}$----equ. 2 Where

$\mathrm{X}_{1}=$ cutting speed $\mathrm{m} / \mathrm{min}$

$\mathrm{X}_{2}=$ feed rate $\mathrm{mm} / \mathrm{rev}$

$\mathrm{X}_{3}=$ depth of cut $\mathrm{mm}$

\section{Statistical Analysis}

The effects of cutting speed, feed rate, and depth of cut on temperature rise were experimentally investigated and calculated with a statistical analysis of variance (ANOVA) were performed. The ANOVAs (Table 4) shows that the parameter experimented have been significant effect and it is sufficient.

Table 4: ANOVA for Response Surface Quadratic Model Analysis of variance table [Partial sum of squares - Type III]

\begin{tabular}{|c|c|c|c|c|c|c|}
\hline Source & Sum of Squares & df & Mean Square & F Value & $P$-value Prob > F & \\
\hline Model & 346.37 & 9 & 38.49 & 4.62 & 0.0280 & significant \\
\hline A-cutting speed & 42.32 & 1 & 42.32 & 5.08 & 0.0588 & \\
\hline B-feed rate & 61.61 & 1 & 61.61 & 7.40 & 0.0298 & \\
\hline C-depth of cut & 0.13 & 1 & 0.13 & 0.015 & 0.9059 & \\
\hline$A B$ & 14.44 & 1 & 14.44 & 1.73 & 0.2293 & \\
\hline$A C$ & 9.61 & 1 & 9.61 & 1.15 & 0.3183 & \\
\hline $\mathrm{BC}$ & 0.040 & 1 & 0.040 & 4.804E-003 & 0.9467 & \\
\hline $\mathrm{A} 2$ & 214.95 & 1 & 214.95 & 25.82 & 0.0014 & \\
\hline B2 & 1.30 & 1 & 1.30 & 0.16 & 0.7048 & \\
\hline C2 & 1.03 & 1 & 1.03 & 0.12 & 0.7352 & \\
\hline Residual & 58.28 & 7 & 8.33 & & & \\
\hline Lack of Fit & 53.43 & 3 & 17.81 & 14.68 & 0.0126 & \\
\hline Pure Error & 4.85 & 4 & 1.21 & & & \\
\hline Cor Total & 404.65 & 16 & & & & \\
\hline
\end{tabular}


Zeelan Basha et al.,

\section{RESULTS AND DISCUSSION}

Interaction Effect of Cutting Speed on Temperature Rise

From the (Figure 6) it is noticed that feed rate has the direct influence on temperature rise at lower cutting speed. This may be due to the fact that as the feed rate increases, the speed of cutting tool movement relative to the work piece also increases resulting in higher temperature rise; An increasing cutting speed results in increasing the cutting temperature rise to a point where

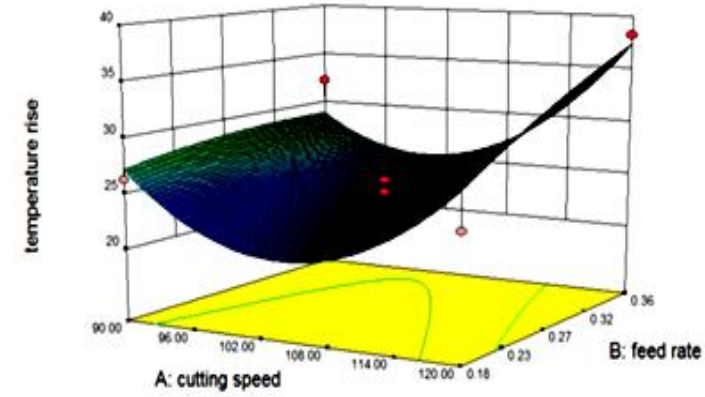

Sci. Technol. Arts Res. J., Oct-Dec 2014, 3(4): 158-164

atomic diffusion between the tool and work piece material takes place, which in turn propagates the tool wear. The temperature rise slightly increases with decreasing cutting speed from 96 to $90 \mathrm{~m} / \mathrm{min}$; this may be due to the adhesion of work material on the tool, which results in more friction. From the change of levels in the figure 2 observed that, which shows that the cutting speed resulted in a decrease in temperature rise from 96 to $104 \mathrm{~m} / \mathrm{min}$, increase in temperature from 114 to 120 $\mathrm{m} / \mathrm{min}$, and optimal in between 104 and $106 \mathrm{~m} / \mathrm{min}$.

Figure 6: Interaction and direct effect of cutting speed

Interaction Effect of Feed Rate on Temperature Rise

From (Figure 7) and (Figure 8) shows that the interaction effects of feed rate and depth of cut on temperature rise are less significant. It has been concluded from the interaction effect that Increasing feed rate and depth of cut increases the temperature rise. This may be due to the fact that, when feed rate and depth of

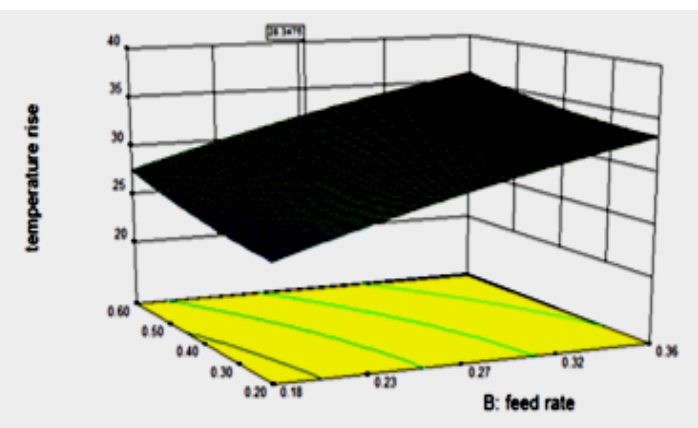

Figure 7: Interaction and direct effect of feed rate

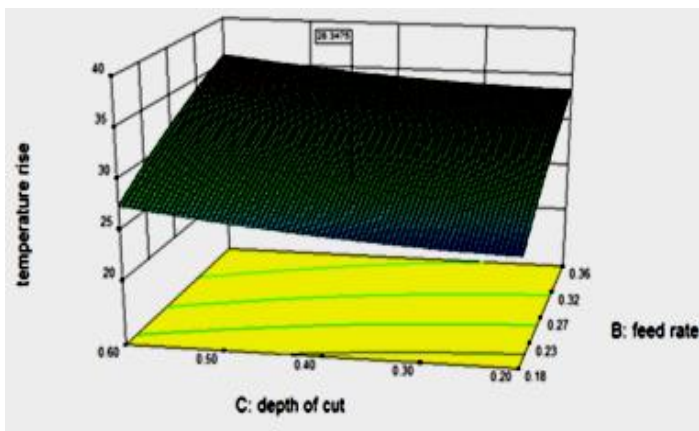

Figure 8: Interaction and direct effect of depth of cut

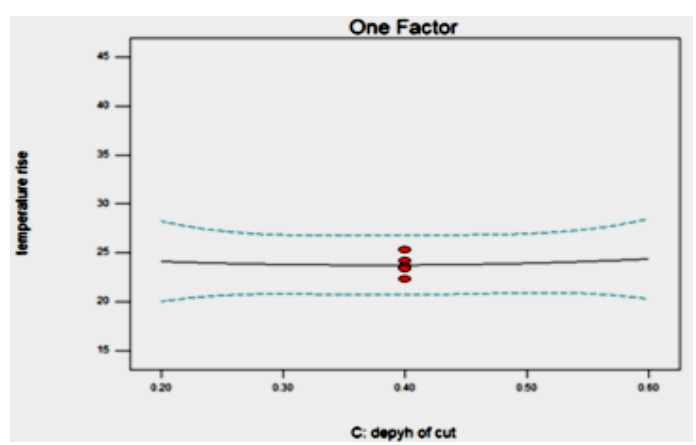

Validation of the Model

The (Table 5) shows that a regression model developed using Box-Behnken by RSM of design of experiment were verified using confirmatory test. It shows the comparison of predicted vs experimental value of temperature rise for the cutting parameters. The percentage of error is found to be within $\pm 3 \%$ which shows the validity of the model. 
Zeelan Basha et al.,

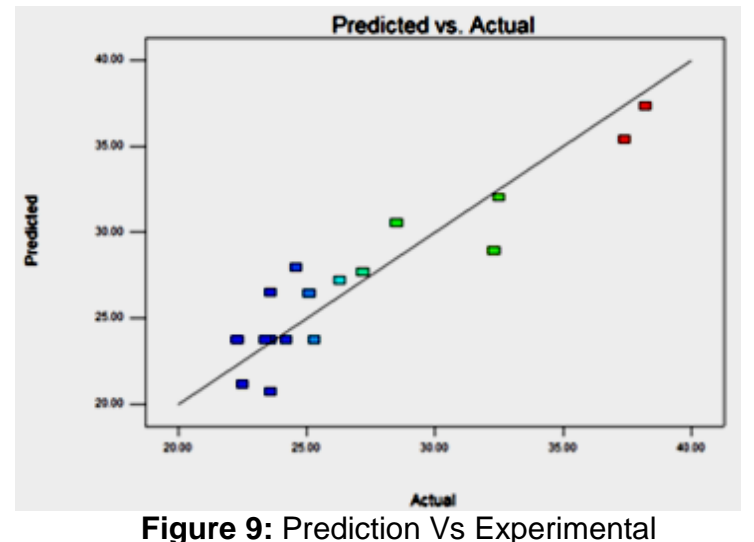

Table 5: Validation of observed Vs predicted

\begin{tabular}{|c|c|c|c|c|c|c|}
\hline \multirow{2}{*}{ 言 } & \multicolumn{3}{|c|}{$\begin{array}{c}\text { Cutting } \\
\text { Parameters }\end{array}$} & \multicolumn{2}{|c|}{$\begin{array}{c}\text { Responses } \\
\text { (temperature rise) }\end{array}$} & \multirow{2}{*}{ 흔 } \\
\hline & $\begin{array}{l}\text { X1: } \\
(-1)\end{array}$ & $\begin{array}{l}\text { X2: } \\
(0)\end{array}$ & $\begin{array}{l}\text { X3: } \\
\text { (1) }\end{array}$ & Observed & Predicted & \\
\hline 1 & 96 & 0.20 & 0.20 & 25.2 & 24.57 & 2.5 \\
\hline 2 & 114 & 0.24 & 0.25 & 26.1 & 25.8 & 1.14 \\
\hline 3 & 96 & 0.18 & 0.30 & 23.1 & 23.24 & -0.6 \\
\hline
\end{tabular}

\section{CONCLUSIONS}

Based on the experimental investigation, application of RSM and Box-Behnken for modeling and optimization of temperature rise of turning process has been discussed. Mathematical model equations were derived for temperature rises by using mathematical software package DESIGN EXPERT 8.0. The confirmatory test shows the predicted values from the model equations were found to be good agreement with observed values and the percentage of error is found to be within $\pm 3 \%$.Considering the factors such as cutting speed, feed rate and depth of cut using design of experiments concept the following conclusions are drawn; The cutting speed, feed rate and depth of cut were the most important parameters to be considered for reducing the temperature rise of the turning process. For reducing the temperature rise, cutting speed should be between 96 and $114 \mathrm{~m} / \mathrm{min}$, Feed rate should be less than $0.23 \mathrm{~mm} / \mathrm{rev}$, depth of cut should be between 0.20 and $0.30 \mathrm{~mm}$.

\section{ACKNOWLEDGEMENTS}

The authors are grateful to the Management, Department of Mechanical Engineering and Department of Production Engineering, Karunya University, Coimbatore, India.

\section{REFERENCES}

Amit Sharma., Vinod Yadava., (2012). Modelling and optimization of cut quality during pulsed Nd:YAG laser cutting of thin Al-alloy sheet for straight profile. Optics and Laser Technology 44: 159-168.

Angus, J., (2011).Robust cutting parameters optimization for production time via computer experiment. Applied Mathematical Modelling 35: 1354-1362.

Baskar, N., Asokan, P., Saravanan, R., Prabhaharan, G. (2005). Optimization of Machining Parameters for milling operations using non-conventional methods. International Journal of Advanced Manufacturing Technology 25: 10781088.
Sci. Technol. Arts Res. J., Oct-Dec 2014, 3(4): 158-164

Conceicao Antonio, C.A., Castro, C.F., Davim,J. P., (2009). Optimisation of multi-pass cutting parameters in facemilling based on genetic search. International Journal of Advanced Manufacturing Technology 44:1106-1115.

Davi Sampaio Correia., Cristiene Vasconcelos Goncalves., Sebastiao Simoes da Cunha, Jr., Valtair Antonio Ferraresi., (2005). Comparison between genetic algorithms and response surfacemethodology in GMAW welding optimization. Journal of Materials Processing Technology 160: 70-76.

Dhupal, D., Doloi, B., Bhattacharyya, B.,(2009). Modeling and optimization on Nd:YAG laser turned micro-grooving of cylindrical ceramic material. Optics and Lasers in Engineering 47: 917-925.

Dilbag Singh, P., Venkateswara Rao (2007). A surface roughness prediction model for hard turning process. International Journal of Advanced Manufacturing Technology 32: 1115-1124.

Gaitondea, V.N., Karnikb, S.R., Paulo Davimc, J., (2008). Taguchi multiple-performance characteristics optimization in drilling of medium density fibreboard (MDF) to minimize delamination using utility concept. Journal of Materials Processing Technology 196:73-78.

Keka Sinha., Papita Das Saha., Siddhartha Datta., (2012). Extraction of natural dye from petals of Flame of forest (Buteamonosperma) flower: Process optimization using response surface methodology (RSM). Dyes and Pigments 94: 212-216.

Mahesh, G., Muthu, S., Devadasan, S.R., (2012). Experimentation and Prediction of Vibration Amplitudein End Milling with Reference to Radial Rake Angle. International Review of Mechanical Engineering 6(6): 1164-1174

Palanisamy, P., Rajendran, I., Shanmugasundaram, S. (2007). Optimization of machining parameters using genetic algorithm and experimental validation for endmilling operations. International Journal of Advanced Manufacturing Technology 32: 644-655.

Routara, C., Bandyopadhyay, A., Sahoo, P., (2009). Roughness modeling and optimization in CNC end milling using response surface method: effect of workpiecematerial variation. International Journal of Advanced Manufacturing Technology 40:1166-1180.

Sivasakthivel, P.S., Sudhakaran, R. (2013). Optimization of machining parameters on temperature rise in end milling of Al 6063 using response surface methodology and genetic algorithm. International Journal of Advanced Manufacturing Technology 67: 2313-2323.

Viktor, P. Astakhov (2007). Effects of the cutting feed, depth of cut, and work piece(bore) diameter on the tool wear rate. International Journal of Advanced Manufacturing Technology 34: 631-640.

Xiao Wang., Xinhua Song., Minfeng Jiang., Pin Li., Yang Hu., Kai Wang., Huixia Liu. (2012). Modeling and optimization of laser transmission joining process between PET and $316 \mathrm{~L}$ stainless steel using response surface methodology. Optics and Laser Technology 44: 656-663.

Zeelan Basha N., Selva Ganesh Kumar., Endalkachew Mosisa. (2013). Determining the Effect of Cutting Parameters on Surface Roughness Using Genetic Algorithm. Science, Technology and Arts Research Journal 2(4): 98-101. 